\title{
Folate receptor mediated delivery of InP quantum dots for bioimaging using confocal and two-photon microscopy
}

Dhruba J Bharali, Derrick W. Lucey, Harishankar Jayakumar, Haridas E. Pudavar and Paras $N$ Prasad*

\section{TEM Images:}

TEM images of InP and InP/ZnS particles are shown here. TEM images of InP/ZnSFolic acid partilcles are shown in the manuscript.
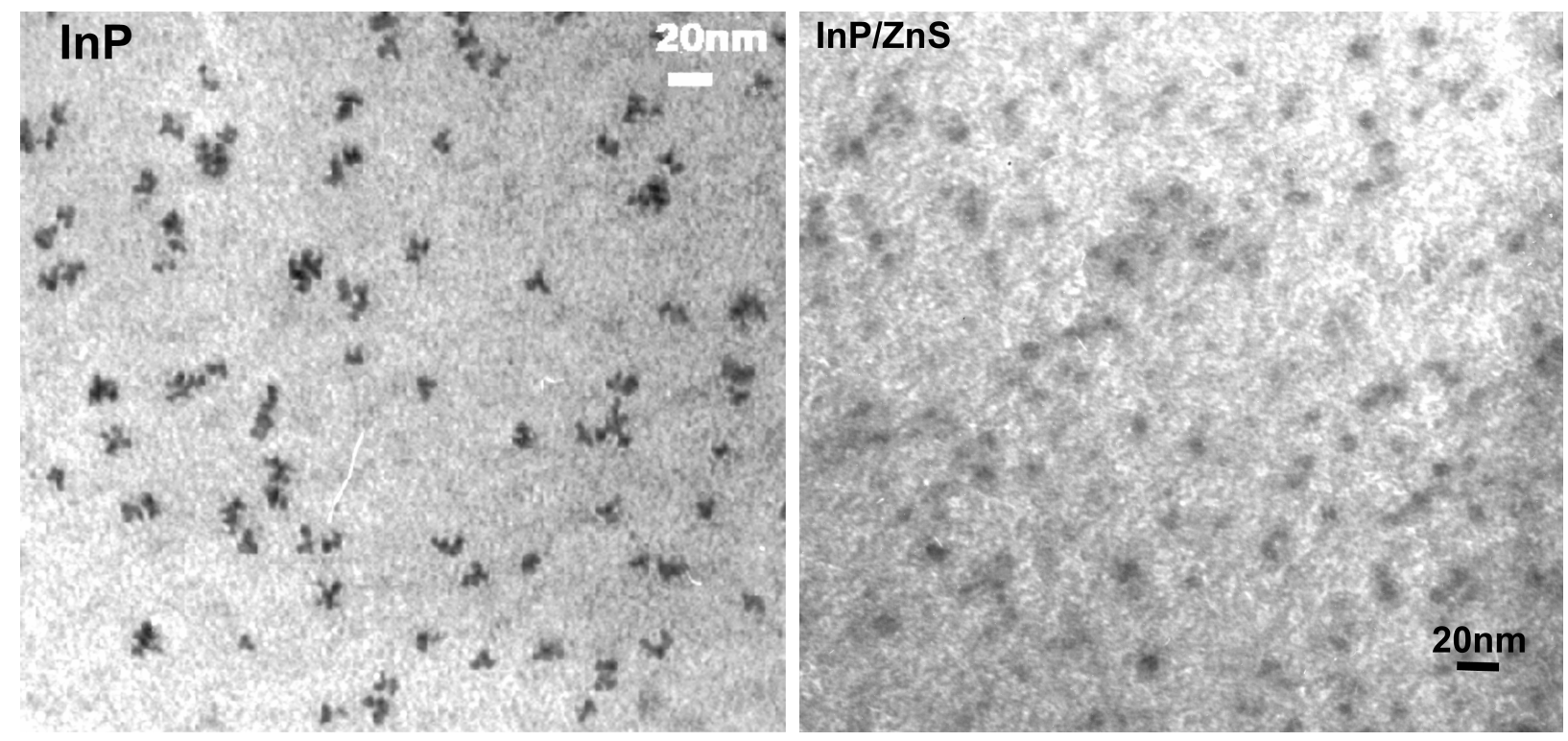

Figure. S1. TEM images of InP and InP/ZnS nanoparticles. 


\section{QD-FA uptake in receptor negative MCF-7 cells:}

Human breast cancer cell line MCF-7 cells (ATCC, HTB-22) which are also known to be folate receptor $(\mathrm{FR})$ negative $^{1}$ were maintained in minimum essential media with $10 \%$ FBS, according to the manufacturers instructions (American Type Culture Collection). To study the uptake and imaging of the conjugated folic acid, the cells were trypsinized and resuspended in the corresponding suitable media at a concentration of around $7.5 \times 10^{5} \mathrm{ml}^{-1}$. Then $60 \mu \mathrm{l}$ of this suspension was transferred to each $35 \mathrm{~mm}$ culture plate and $2 \mathrm{ml}$ of the corresponding full medium was added. These plates were then placed in an incubator at $37{ }^{\circ} \mathrm{C}$ with $5 \% \mathrm{CO}_{2}$ (VWR Scientific, model 2400). After 36 hours of incubation, the cells ( $50 \%$ confluency) were rinsed with PBS, and $2 \mathrm{ml}$ of the correspond ing fresh media was added to the plates. Finally, $100 \mu \mathrm{l}$ of QD-FA was added and mixed properly. Plates were returned to the incubator $\left(37{ }^{\circ} \mathrm{C}, 5 \% \mathrm{CO}_{2}\right)$ for the required incubation period. After each specific time interval of incubation, the plates were taken out, rinsed several times with sterile PBS and $2 \mathrm{ml}$ of fresh serum free medium was added. The plates were incubated for another 10 minutes at $37^{\circ} \mathrm{C}$ and were directly imaged under our confocal microscope.

Confocal images of the internalized QD-FA inside the cells were obtained after different time intervals of incubation. The confocal fluorescence image s of MCF cells treated with QD-FA at the time interval of 1, 3 and 6 hours are shown in Figure S2.

The MCF-7 cells didn't show any significant uptake of QD-FA in 6hrs. This lack of entry of QD-FA into receptor negative MCF-7 cell line (results similar to A549, another receptor negative cell line) further supports the receptor mediated entry of QD-FA into KB cells (receptor positive). 


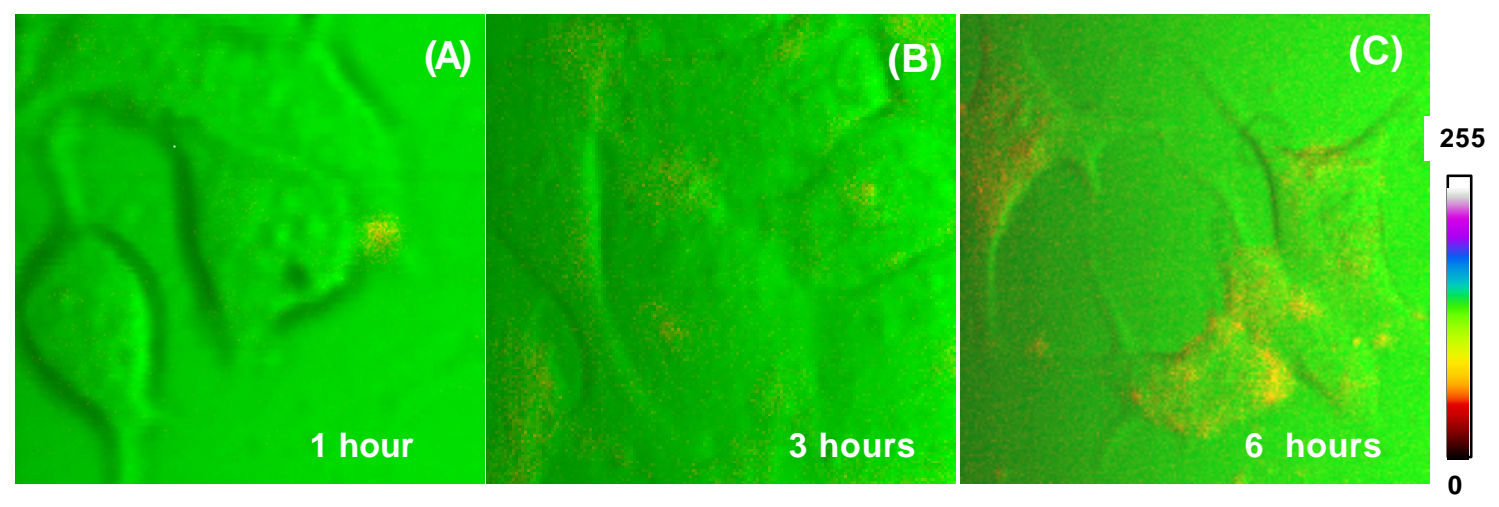

Figure S2. Confocal images showing fluorescence of QD-FA in MCF-7 cells (receptor negative cell line) after 1, 3 and 6 hours of incubation. Here green channel shows the transmission images, while the intensity coded (red to white) channel shows the fluorescence. 


\section{QD-FA uptake in receptor negative A-549 cells:}

Cell culture and maintenance of A-549 cells are described in the main body of the article.

A-549 cells are reported to be folate receptor negative. ${ }^{2}$ Confocal images of the A-549

cells incubated with QD-FA for 1, 3 and 6 hours are shown in Figure S3.
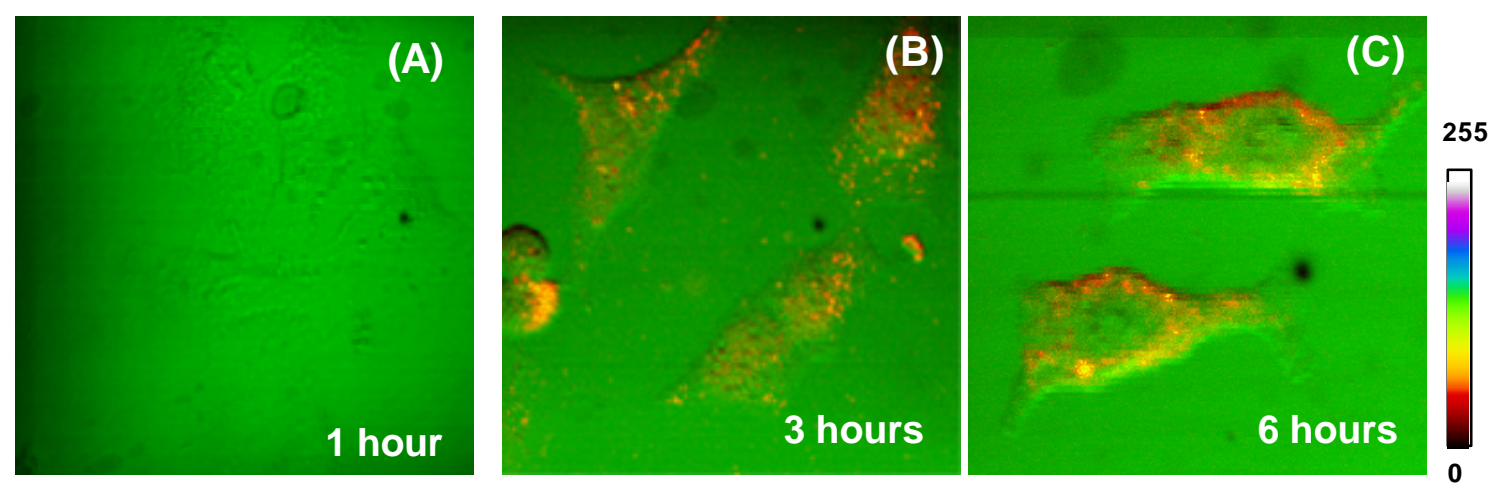

Figure S3. Confocal images showing fluorescence of QD-FA in A-549 cells (receptor negative cell line) after 1, 3 and 6 hours of incubation. Here green channel shows the transmission images, while the intensity coded (red to white) channel shows the fluorescence.

After 1 hour of incubation with QD-FA, the A549 cells do not demonstrate any detectable internalization; however, after three hours, small amounts of internalized QDFA were observed. After longer incubation period (6 hours), A549 cells showed some cytoplasmic staining. This uptake which most likely occurs through an unknown endocytic pathway, is significantly different from the receptor mediated entry in the $\mathrm{KB}$ cells.

\section{References:}

(1) Chung KN, Saikawa Y, Paik TH, Dixon KH, Mulligan T, Cowan KH, Elwood PC., J Clin Invest. 91(4):1289-94 (1993). 
(2) Hoon Choi, Seok Rye Choi, Rong Zhou, Hank F. Kung, I-Wei Chen, Acad. Radiol. 2004, 11, 996-1004. 